\title{
Readiness to deny group's wrongdoing and willingness to fight for its members: the role of Poles' identity fusion with the country and religious group
}

\author{
Tomasz Besta ${ }^{1 \cdot A, B, C, D, E, F, G}$, Ángel Gómez $z^{2 \cdot C, D, E, F, G}$, Alexandra Vázquez $z^{2 \cdot D, E, F, G}$ \\ 1: Institute of Psychology, University of Gdansk, Gdansk, Poland \\ 2: Universidad Nacional de Educación a Distancia, UNED, Spain
}

\section{BACKGROUND}

Identity fusion is a powerful visceral feeling of oneness with the group. Dozens of studies have demonstrated that identity fusion is a powerful predictor of endorsement of extreme behavior for the group. However, most research has been conducted with Spanish and/or North-American participants, and focused on the country as the target group.

PARTICIPANTS AND PROCEDURE

Two correlational studies were conducted with Polish participants, using measures of identity fusion, group identification, willingness to fight and die for ingroup members and readiness to deny group's wrongdoing.

\section{RESULTS}

We replicate and extend previous findings by showing that fusion with the country also predicts endorsement of extreme pro-ingroup behaviors with Polish participants (Study 1). Interestingly, fusion with religious group predicts willingness to endorse pro-ingroup behaviors for the religion they practice (Study 2). In addition, the present research shows that strongly fused participants display high levels of readiness to deny the group's wrongdoing, when the target group is the country (Study 1) or religious group (Study 2).

\section{CONCLUSIONS}

These findings replicate and extend previous research and are a valuable contribution to the identity fusion theory.

\section{KEY WORDS}

social identity; identity fusion; extremism; attitudes

CORResPonding AUthor - Tomasz Besta, PhD, Institute of Psychology, University of Gdansk, 4 Bażyńskiego Str., 80-952 Gdansk, e-mail: t.besta@ug.edu.pl

authors' CONTRibution - A: Study design - B: Data collection - C: Statistical analysis - D: Data interpretation . E: Manuscript preparation · F: Literature search · G: Funds collection

to Cite this ARTICLE - Besta, T., Gómez, Á. \& Vázquez, A. (2014). Readiness to deny group's wrongdoing and willingness to fight for its members: the role of the Poles' identity fusion with the country and religious group. Current Issues in Personality Psychology, 2(1), 49-55. 


\section{BACKGROUND}

Identity fusion entails a visceral feeling of oneness with the group that has consistently proven to be a strong predictor of extreme pro-group behavior (see Swann, Jetten, Gómez, Whitehouse \& Bastian, 2012). Being fused with a group involves a powerful union of the personal and social self wherein the borders between the two become porous. As a consequence, the personal and social identities of fused persons combine synergistically to motivate progroup behavior. Activating either personal or social self-views engenders equivalent responses (i.e. high levels of willingness to fight and die for the group, willingness to self-sacrifice for ingroup members) among fused persons.

So far, research on identity fusion has been mainly focused on extended groups as the country (see Buhrmester et al., 2012 for an exception) and most studies have been conducted in Spain or in the United States (see Swann et al., in press a, for an exception). Although the evidence on the link between identity fusion with one's country and extreme progroup behavior is strong, more research is needed to check whether previous findings are valid in other countries or when groups of different nature are considered. The present research aims to fill this gap in the literature by exploring fusion with Poland and fusion with one's religious group. In particular, the current work has two main goals. The first goal is to check whether the predicted link between identity fusion and endorsement of extreme behavior emerges within the Polish population. The second goal is to investigate whether being fused with one's religious group has the same consequences as being fused with a country.

A growing literature has consistently demonstrated the capacity of measures of identity fusion to predict pro-ingroup behaviors. For example, strongly fused persons are especially willing to (a) endorse physically fighting and dying for their country (Gómez et al. 2011a; Gómez, Morales, Hart, Vázquez \& Swann, 2011b; Swann, Gómez, Seyle, Morales \& Huici, 2009), (b) self-sacrifice to save the lives of members of their country in intergroup variations of the trolley dilemma (Gómez et al., 2011a; Swann et al., in press b; Swann, Gómez, Dovidio, Hart \& Jetten, 2010a), and (c) to donate to fellow Spaniards in need of financial help (Swann, Gómez, Huici, Morales \& Hixon, 2010b). Furthermore, recent evidence indicates that apparently, for strongly fused persons, recognizing that other group members share biological (i.e. genes) or psychological (i.e. values) core characteristics makes extended groups as the country seem "family like" and worth dying for (Swann, et al., in press a). Swann et al. (in press a) recently showed that identity fusion predicts willingness to endorse pro-ingroup behavior in countries of the six continents, including Poland.
Here we will try to replicate these results and also to explore whether identity fusion predicts an unexplored outcome variable readiness to deny the group's wrongdoing. Accepting that the group has done something bad could lead weakly fused individuals to distance themselves or abandon the group. However, for strongly fused individuals, de-fusion is only possible at the expense of a huge emotional conflict, as it would imply restructuring the self-concept, one's relations with others and the meaning of one's actions (Swann et al., 2012). A less costly strategy to recover coherence with one's values and attitudes, that also has the advantage of maintaining one's relationship with the group untouched, is denying the group's negative actions. Thus, we predict that highly fused participants will show more readiness to deny the group's wrongdoing than weakly fused ones.

As mentioned, as well as extending research on identity fusion to other outcome variables, the present research aims to examine fusion with religious groups. Religion has been a ubiquitous feature of human societies throughout history (Kimball, 2002; Silberman, 2005). In Poland, religion plays a crucial role. In the Gallup Poll of 2012, 66\% of Polish participants answered yes to the question of whether religion is important in your daily life. Most people worldwide claim to be followers of a religious tradition (Kimball, 2002) and some are willing to take their faith to the end (see Swann et al., in press a). Swann et al. (in press a) showed that, for strongly fused persons, recognizing that other group members share core values makes extended groups as the country seem "family like" and worth dying for. When shared values are linked to religion, highly fused individuals could be tempted to engage in extreme behavior to defend their religious group against threats. In fact, some of the most paradigmatic examples of extreme behavior, terrorist acts, are usually performed in the name of a religion (Loza, 2007). The current research examines the link between fusion with a religious group and endorsement of extreme behavior for the first time. We hypothesized that fusion with a religious group will predict endorsement of extreme behavior for that group and readiness to deny the group's wrongdoing.

\section{PRESENT STUDIES}

To test these hypotheses we conducted two correlational studies. We began by replicating previous findings by testing whether identity fusion is a better predictor of endorsement of extreme behaviors for the group than group identification in a sample of Polish participants. Then, we tested whether identity fusion is also predictive of readiness to deny the group's wrongdoing (Study 1). Importantly, we examine whether the effect of identity fusion on en- 
dorsement of extreme behaviors and readiness to deny the group's wrongdoing are also extended to the religious group. We predict that participants strongly fused with their religious group will be more willing to endorse extreme pro-group behaviors, and deny the group's wrongdoing (Study 2). We also expect that these effects will be maintained when controlling for age and gender (Studies $1 \& 2$ ), and also for the kind of religion (Study 2).

\section{STUDY 1}

\section{Participants and procedure}

\section{Participants}

Three hundred and sixty-five Polish undergraduates (197 female, $M_{\text {age }}=21.81, S D=4.46$ ) participated online in the present study for course credits, and they were asked to recruit another opposite sex student of similar age from a different field of study or family member. All questionnaires were in Polish.

\section{Procedure}

Participants were introduced to a study directed to explore the relationship between identity and attitudes toward their country. Then participants completed a questionnaire including four scales: fusion and identification with the country, endorsement of extreme pro-group behavior, and readiness to deny the group's wrongdoing. Respondents indicated the degree of agreement with each statement on scales ranging from 0 (strongly disagree) to 6 (strongly agree).

Fusion with the country was measured using the 7-item verbal fusion scale (Gómez et al., 2011a). Example items are "I am one with my country" and "I am strong because of my country" ( $\left.\alpha^{\prime}=0.91\right)^{1}$. We used word "country" instead of, for example, "nation" as this is an established terminology used in many studies and our main goal was to replicate results of previous research (where this wording was applied).

Identification with the country was measured using the 6-item scale by Mael \& Ashforth (1992). Example items are "Successes of my country are my successes" and "I am very interested in what citizens of other countries think about my country" ( $\alpha=0.88)$.

Endorsement of extreme pro-group behavior was measured using the 7-item scale by Swann et al. (2009). Example items are: "I would fight someone physically threatening another Pole" and "I would fight someone insulting or making fun of Poland" ( $\alpha=0.85)$.

Readiness to deny the group's wrongdoing was measured by a 3-item scale: "My country would never do anything bad", "My country would never do anything that would hurt me", and "My country has never done anything it should be ashamed of" ( $\alpha=0.83)$.

\section{Results}

Correlation analyses indicated that, as expected, identity fusion was correlated with endorsement of extreme pro-group behavior, $r(363)=0.61, p<0.001$, and readiness to deny the group's wrongdoing, $r(363)$ $=0.39, p<0.001$, respectively. Group identification was also related to willingness to endorse extreme pro-group behavior, $r(363)=0.51, p<0.001$, and readiness to deny the group's wrongdoing, $r(363)=0.30$, $p<0.001$. As in previous research, fusion was correlated with group identification, $r(363)=0.68, p<0.001$. However, calculations for the test of the difference between two independent correlation coefficients indicated that the correlations between fusion and the outcome measures were stronger than the correlations between identification and the outcome measures, $z=1.97, p=0.020$, and $z=1.38, p=0.080$ for endorsement of extreme pro-group behavior and readiness to deny the group's wrongdoing respectively. Also, regression analyses indicated that there were no problems of collinearity; all variance inflation factors (VIFs) $<2.1$.

To replicate and extend previous findings about identity fusion, a pair of hierarchical regressions was conducted. The first regression tested the effects of identity fusion and group identification on endorsement of extreme pro-group behavior. The second regression explored their effects on readiness to deny the group's wrongdoing. We controlled for gender (dummy coded $0=$ male, 1 = female) and age, introducing them in the first step of the regression ${ }^{2}$.

Endorsement of extreme pro-group behavior. As Table 1 shows, when controlling for gender and age, fusion and identification significantly predicted endorsement of extreme pro-group behavior (standardized coefficients $\beta=0.44$ and 0.21 respectively).

However, fusion was a stronger predictor than identification (the standardized $\beta$ indicates that the effect was double). In addition, gender was related to endorsement of extreme pro-group behavior such that males displayed more willingness to endorse extreme pro-group behaviors than females, $M=2.38$ $(S D=1.33)$ vs. $M=1.84(S D=1.02), t(363)=4.36, p<0.001$ (equal variances not assumed).

Readiness to deny group's wrongdoing. As shown in Table 1, when controlling for sex and age, fusion significantly predicted readiness to deny the group's wrongdoing (standardized coefficients $\beta=0.36$ ), with more fusion leading to more endorsement of extreme behavior. No other effect was significant, $p>0.110$.

\section{Discussion}

Results of this study replicate previous findings showing that identity fusion is a better predictor of endorsement of extreme pro-group behavior than group identification, controlling for age and gender 
(see Gómez et al., 2011a; Swann et al., 2009; in press a). The greater willingness of men to endorse extreme pro-group behaviors as compared to women also replicates previous results (see Swann et al., in press a, Studies 1-4), and is consistent with past work indicating that men tend to be more physically aggressive (Eagly \& Steffen, 1986) and are more likely to rescue others in emergency situations (Lyons, 2005), in particular when physical prowess is required (Becker \& Eagly, 2004).

In addition, Study 1 introduces a new outcome measure relevant for the identity fusion domain, readiness to deny the group's wrongdoing. Results showed that strongly fused participants expressed higher levels of readiness to deny the group's wrongdoing. Thus, strongly fused individuals think that their country cannot do anything that could hurt them or that they should be ashamed of. This reluctance to admit that the group could do something that would damage them might explain why fused individuals increase their willingness to endorse extreme pro-in-group behaviors when they are excluded in general, and when the source of the exclusion is their own group in particular (Gómez et al., 2011b).

Study 1 and most of the previous research focused on fusion with extended groups (see Swann et al., 2012) as the country (see Buhrmester et al., 2012; and Swann et al., 2014, for some exceptions). The main goal of the next study is to test the effects of being fused with a religious group. In particular, we want to determine whether individuals strongly fused with their religious group are more willing to endorse extreme pro-group behavior for their in-group members and deny the group's wrongdoing than weakly fused ones.

\section{STUDY 2}

\section{Participants and procedure}

\section{Participants}

One hundred and thirty-eight Polish undergraduates and their adult family members (69 female, $M_{\text {age }}=$ $26.88, S D=4.76)$ participated online for course credits. All questionnaires were in Polish.

\section{Procedure}

After a short introduction from which participants learned that the study was being performed to explore relationships between personality, identity and attitudes, participants completed a questionnaire. All measures were the same as in Study 1 but with appropriately adapted wording: identity fusion with religious group (i.e. "I am one with my religious group”), religious group identification (i.e. "I am very interested in what people of different faiths think about my religion"), endorsement of extreme behavior for one's religious group (i.e. "I would fight someone physically threatening another member of my religious community" and "I would fight someone insulting or making fun of my religion") and readiness to deny the group's wrongdoing (i.e. "My religious group would never do anything bad"). Respondents indicated their degree of agreement with each statement on scales ranging from 0 (strongly disagree) to 6 (strongly agree). Reliability of the scales was as follows: identity fusion $(\alpha=0.96)$; group identification ( $\alpha=0.93$ ), endorsement of extreme behavior for one's religious group ( $\alpha=0.91)$; and readiness to deny the group's wrongdoing $(\alpha=0.94)$.

As regards religious affiliation, $68.8 \%(n=95)$ of participants were Roman Catholics, $21 \%(n=29)$ stated that they are atheists/agnostics, and $10.2 \%(n=14)$

Table 1

Hierarchical multiple regression analysis with enter method for variables predicting endorsement of extreme pro-group behavior for a country and readiness to deny group's wrongdoing in Study 1

\begin{tabular}{|c|c|c|c|c|c|c|}
\hline \multirow[t]{2}{*}{ Predictor } & \multicolumn{3}{|c|}{$\begin{array}{c}\text { Endorsement of extreme } \\
\text { pro-group behavior }\end{array}$} & \multicolumn{3}{|c|}{$\begin{array}{c}\text { Readiness to deny group's } \\
\text { wrongdoing }\end{array}$} \\
\hline & $\Delta R^{2}$ & $\beta$ & $t$ & $\Delta R^{2}$ & $\beta$ & $t$ \\
\hline Step 1 & 0.05 & & & 0.01 & & \\
\hline Gender & & -0.23 & $-4.40^{* * *}$ & & 0.01 & 0.08 \\
\hline Age & & 0.01 & 0.20 & & 0.09 & 1.64 \\
\hline Step 2 & $0.36^{* * *}$ & & & $0.16^{* * *}$ & & \\
\hline Fusion & & 0.44 & $7.67^{* * *}$ & & 0.36 & $5.29^{* * *}$ \\
\hline Identification & & 0.21 & $3.75^{* * *}$ & & 0.05 & 0.80 \\
\hline Adjusted $R^{2}$ & $0.41^{* * *}$ & & & $0.16^{* * *}$ & & \\
\hline$n$ & 365 & & & 365 & & \\
\hline
\end{tabular}

Note. ${ }^{* * *} p<0.001$. All VIFs $<2.1$. 
Tomasz Besta, Ángel Gómez, Alexandra Vázquez

Table 2

Summary of mean results and standard deviations in Study 1 and Study 2

\begin{tabular}{cccccccccc}
\hline \multirow{2}{*}{ Scale } & \multicolumn{3}{c}{ Study 1 } & \multicolumn{7}{c}{ Study 2 } \\
\cline { 2 - 9 } & \multicolumn{3}{c}{ All participants } & \multicolumn{3}{c}{ All participants } & \multicolumn{3}{c}{ Roman Catholics only } \\
\cline { 2 - 9 } & $n$ & $M$ & $S D$ & $n$ & $M$ & $S D$ & $n$ & $M$ & $S D$ \\
\hline $\begin{array}{c}\text { Identity } \\
\text { fusion }\end{array}$ & 365 & 2.70 & 1.34 & 109 & 2.05 & 1.60 & 95 & 2.10 & 1.61 \\
$\quad \begin{array}{c}\text { Group } \\
\text { identification }\end{array}$ & 365 & 3.52 & 1.33 & 109 & 2.10 & 1.61 & 95 & 2.14 & 1.60 \\
$\begin{array}{c}\text { Endorsement of } \\
\text { extreme behavior }\end{array}$ & 365 & 2.10 & 1.20 & 109 & 1.44 & 1.17 & 95 & 1.50 & 1.17 \\
$\quad \begin{array}{c}\text { Group } \\
\text { denial }\end{array}$ & 365 & 1.44 & 1.23 & 109 & 2.25 & 1.75 & 95 & 2.31 & 1.75 \\
\hline
\end{tabular}

Note. Potential range of all scales: from 0 (minimum) to 6 (maximum). In Study 1 the target group is the country, in Study 2 one's

religious group.

were from other religious traditions (e.g. Protestant $=$ $=1$; Muslim $=1$; Jehovah Witness $=2$; Buddhist $=1$; 9 persons were theists with no declared religious affiliations). To maintain homogeneity of the sample atheists/agnostics were excluded from the analyses; thus 109 participants were included in the final sample (61 female, $M_{\text {age }}=26.76, S D=4.93$ ).

Results

Preliminary analyses revealed that mean results on scales related to relationship with the religious group were lower than those from the country context in Study 1 (except on the group denial scale). Specific mean results are presented in Table 2. Intercorrelations between variables related to religious group were high. Personal and identity fusion with the religious group was linked to identification with the religious group as measured by the Meal and Ashforth scale $r(107)=0.88, p<0.001$; to endorsement of extreme behavior for the religious group $r(107)=0.80$, $p<0.001$; and to religious group denial $r(107)=0.73$, $p<0.001$. Identification with the religious group was also related to endorsement of extreme behavior $r(107)=0.75, p<0.001$, and to the denial of wrongdoing $r(107)=0.65, p<0.001$. The correlation test indicated that the differences between correlations did not reach statistical significance $(z=0.91, p=0.180$, and $z=1.12, p=0.130$ for endorsement of extreme progroup behavior and readiness to deny the group's wrongdoing respectively).

To test our hypothesis a pair of hierarchical regressions was conducted. The first regression tested the effect of identity fusion on endorsement of extreme pro-group behavior. The second regression explored its effect on readiness to deny the group's wrongdoing. We controlled for gender (dummy cod- ed $0=$ male, 1 = female), and age, introducing them in the first step of the regression, and participants' religious denomination/tradition (majority religion Catholic $=1$ vs. minority denominations $=0$ ), introducing them in the second step of the regression. In a third step we introduced identity fusion and identification with the religious group.

Endorsement of extreme behavior for one's religious group. As can be seen in Table 3, identity fusion predicted endorsement of extreme behavior for one's religious group when controlling for gender, age and participants' religious tradition (standardized coefficients $\beta=0.60$ ).

Readiness to deny group's wrongdoing. Results shown in Table 3 also indicate that identity fusion predicted readiness to deny the group's wrongdoing. When controlling for sex, age and participants' religious tradition, stronger identity fusion leads to a higher level of readiness to deny the group's wrongdoing (standardized coefficients $\beta=0.69$ ).

\section{Discussion}

We can speculate that strong intercorrelations between all variables related to the religious group emerged because of the low mean results on all of the scales and small variation of the participant's answers. However, it should be noted that despite this, regression analyses indicated that there were no problems of collinearity. Results of Study 2 represent a test of convergent validation by showing that identity fusion is also predictive of willingness to deny the group's wrongdoing and display extreme behaviors for a religious group, as it is for a national group (Swann et al., 2012). Individuals who are strongly fused with a religious group are particularly willing to endorse extreme behaviors for their religious group and are 
Table 3

Hierarchical multiple regression analysis with enter method for variables predicting endorsement of extreme pro-group behavior for a religious group and readiness to deny group's wrong doing in Study 2

\begin{tabular}{|c|c|c|c|c|c|c|}
\hline \multirow[t]{2}{*}{ Predictor } & \multicolumn{3}{|c|}{$\begin{array}{c}\text { Endorsement of extreme } \\
\text { pro-group behavior }\end{array}$} & \multicolumn{3}{|c|}{$\begin{array}{l}\text { Readiness to deny group's } \\
\text { wrongdoing }\end{array}$} \\
\hline & $\Delta R^{2}$ & $\beta$ & $t$ & $\Delta R^{2}$ & $\beta$ & $t$ \\
\hline Step 1 & 0.02 & & & 0.02 & & \\
\hline Gender & & -0.01 & -0.13 & & -0.09 & -0.96 \\
\hline Age & & 0.132 & 1.37 & & 0.12 & 1.24 \\
\hline Step 2 & 0.02 & & & 0.01 & & \\
\hline Catholic & & 0.15 & 1.52 & & 0.10 & 1.01 \\
\hline Step 3 & $0.61^{* * *}$ & & & $0.52^{* * *}$ & & \\
\hline Fusion & & 0.60 & $4.72^{* * *}$ & & 0.69 & $4.81^{* * *}$ \\
\hline Identification & & 0.22 & $1.76^{\mathrm{t}}$ & & 0.05 & 0.34 \\
\hline Adjusted $R^{2}$ & $0.63^{* * *}$ & & & $0.52^{* * *}$ & & \\
\hline$n$ & 109 & & & 109 & & \\
\hline
\end{tabular}

Note. ${ }^{\mathrm{t}} p=0.08 ;{ }^{* * *} p<0.001$. All VIFs $<4.72$.

ready to deny the group's wrongdoing, as happened in Study 1 when the country was considered as the target group.

\section{DISCUSSION}

Consistently with previous studies, our results indicated that identity fusion predicts endorsement of extreme behavior and readiness to deny the group's wrongdoing in Polish individuals. Importantly, the relationship between fusion and these outcome variables was significant regardless of whether the focal group was the country or religious group.

Even though these results are a valuable contribution to the identity fusion theory, we must note a methodological limitation. The studies included in the present investigation are correlational, so we cannot draw a conclusion about causality between identity fusion and endorsement of extreme behavior. Experimentally manipulating fusion to test its effects on endorsement of extreme behavior might seem the most direct way to establish causal relations. However, as fusion stabilizes the self-concept, it should be stable to a great extent. Thus, longitudinal strategies could be more effective.

To sum up, the presented findings extend previous research in three ways. First, we replicated with a Polish population results from previous studies conducted in other countries indicating that identity fusion is associated with endorsement of extreme behavior. Second, we explored the link between identity fusion and an unexplored outcome variable, readiness to deny the group's wrongdoing. We found that highly fused participants are more willing than weakly fused ones to deny their group's wrongdoing. The irrevocability principle of fusion (Swann et al., 2012) stated that once a person is fused, he/ she is extremely likely to continue being fused in the future. As fusion gives meaning to the personal and social self, de-fusion is a very costly option for strongly fused individuals. In contrast, denial might be a strategy to maintain one's relationship with the group and reduce feelings of collective shame (Lickel, Schmader \& Barquissau, 2004) or guilt (Branscombe, 2004). Future research should empirically search for potential mediators of the relationship between identity fusion and readiness to deny negative group actions. Third, we analyzed fusion with a group that was not considered previously, namely a religious group. Our results showed that fusion with a religious group is positively related to endorsement of extreme behavior. When individuals who are strongly fused with their religious group find a provocative context, they could engage in extreme behavior as a defense against outgroups perceived as threatening. In fact, recent work on sacred values indicates that religion increases ingroup trust but also may increase mistrust and intergroup conflict (Atran \& Ginges, 2012). The interaction between being fused with one's religious group and considering beliefs shared with others professing such religion as sacred values might have tremendous consequences for intragroup cohesion but also for intergroup hostility, and should be seriously considered for future research.

For funds that facilitated the preparation of this article, we acknowledge: National Science Centre in 
Poland grant \#2011/01/D/HS6/02282 to Tomasz Besta, Spanish Ministry of Economy and Competitively grant \#PSI2012-30921 to Ángel Gómez, and 2013-004-UNEDPROY grant to Alexandra Vázquez.

\section{ENDNOTES}

1 Due to an unspecified web page error participants' responses to one item ("I have a deep emotional bond with my country") were not recorded, so the final scale used in this study consisted of 6 items.

2 We controlled for demographic variables because some significant differences emerged (e.g. between men and women in Study 1). However, in both studies regression analyses without controlling for age and gender gave very similar results to those reported here (e.g. in Study 1 the difference between identity fusion and group identification was even stronger with $\beta$ for identity fusion as a predictor of endorsement of extreme pro-group behavior $=0.50$ and $\beta$ for group identification $=0.17$ ).

\section{RefERENCES}

Atran, A. \& Ginges, J. (2012). Religious and sacred imperatives in human conflict. Science, 336, 855-857.

Becker, S.W. \& Eagly, A.H. (2004). The heroism of women and men. American Psychologist, 59, 163-178.

Branscombe, N.B. (2004). A social psychological process perspective on collective guilt. In: N.B. Branscombe \& B. Doosje (eds.). Collective guilt: International perspectives (pp. 320-334). Cambridge, UK: Cambridge University Press.

Buhrmester, M., Gómez, Á., Brooks, M.L., Morales, J.F., Fernández, S., \& Swann, W.B., Jr. (2012). My group's fate is my fate: "Fused" Americans and Spaniards link personal life quality to outcome of '08 elections. Basic and Applied Social Psychology, 34, 527-533.

Eagly, A.H. \& Steffen, V.J. (1986). Gender and aggressive behavior: A metaanalytic review of the social psychological literature. Psychological Bulletin, 100, 309-330.

Gallup Poll (2012). On religion importance. Retrieved from Gallup website: https://worldview.gallup. com/default.aspx

Gómez, A., Brooks, M.L., Buhrmester, M.D., Vázquez, A., Jetten, J. \& Swann, W.B., Jr. (2011a). On the nature of identity fusion: Insights into the construct and a new measure. Journal of Personality and Social Psychology, 100, 918-933.

Gómez, Á., Morales, J.F., Hart, S., Vázquez, A. \& Swann, W.B., Jr. (2011b). Rejected and excluded forevermore, but even more devoted: Irrevocable ostracism intensifies loyalty to the group among identity fused persons. Personality and Social Psychology Bulletin, 37, 1574-1586.

Kimball, C. (2002). When religion becomes evil. San Francisco: Harper San Francisco.

Loza, W. (2007). The psychology of extremism and terrorism: A Middle-Eastern perspective. Aggression and Violent Behavior, 12, 141-155.

Lyons, M. (2005). Who are the heroes? Characteristics of people who rescue others. Journal of Cultural and Evolutionary Psychology, 3, 239-248.

Lickel, B., Schmader, T. \& Barquissau, M. (2004). The evocation of moral emotions in intergroup contexts: The distinction between collective guilt and collective shame. In: N.R. Branscombe \& B. Doosje (eds.). Collective guilt: International perspectives. New York: Cambridge University Press.

Mael, F. \& Ashforth, B.E. (1992). Alumni and their alma mater: A partial test of the reformulated model of organizational identification. Journal of Organizational Behavior, 13, 103-123.

Silberman, I. (2005). Religion as a meaning system: Implications for the new millennium. Journal of Social Issues, 61, 641-663.

Swann, W.B., Buhrmester, M.D., Gómez, M., Jetten, J., Bastian, B., Vázquez, A. \& Zhang, A. (in press a). What makes a group worth dying for? Identity fusion fosters perception of familial ties, promoting self-sacrifice. Journal of Personality and Social Psychology.

Swann, W.B., Jr., Gómez, A., Buhrmester, M.D., LópezRodríguez, L., Jiménez, J. \& Vázquez, A. (in press b). Contemplating the ultimate sacrifice: Identity fusion channels pro-group affect, cognition, and moral decision-making. Journal of Personality and Social Psychology.

Swann, W.B., Jr., Gómez, A., Dovidio, J.F., Hart, S. \& Jetten, J. (2010a). Dying and killing for one's group: Identity fusion moderates responses to intergroup versions of the trolley problem. Psychological Science, 21, 1176-1183.

Swann, W.B., Jr., Gómez, A., Huici, C., Morales, J.F. \& Hixon, J.G. (2010b). Identity fusion and self-sacrifice: Arousal as a catalyst of pro-group fighting, dying, and helping behavior. Journal of Personality and Social Psychology, 99, 824-841.

Swann, W.B., Jr., Gómez, A., Seyle, D.C., Morales, J.F. \& Huici, C. (2009). Identity fusion: The interplay of personal and social identities in extreme group behavior. Journal of Personality and Social Psychology, 96, 995-1011.

Swann, W.B., Jr., Gómez, Á., Vázquez, A., Guillamón, A., Segovia, S. \& Carrillo, B. (2014). Identity and the choices transsexuals make: Fusion with preferred sex predicts sex change surgery. Manuscript submitted for publication.

Swann, W.B., Jr., Jetten, J., Gómez, Á., Whitehouse, H. \& Bastian, B. (2012). When group membership gets personal: A theory of identity fusion. Psychological Review, 119, 441-456. 